\section{THE INDIAN STATISTICAL INSTITUTE}

T HE continued activity and growth during the war period of the Indian Statistical Institute is a striking example of the benefits which may flow from the stimulus of war conditions, when individual initiative is unhampered in putting itself at the service of Government and to meet the needs and deficiencies of existing official organization. Perhaps nowhere than in India have the prevailing conditions been more propitious, or the need greater, for the active use of agencies run at private risk for public purposes.

The Institute, as it has now developed, has many facets : on the educational side equally as a training ground for computors and routine statisticians, and as a centre of postgraduate research in the most farreaching branches of the mathematical theory of statistics and experimental design; as a professional institute and learned society bringing together all schools of thought in Indian statistics; as an agency employed by departments of Government and advisory bodies, in the essential work of collecting, scrutinizing and digesting the facts upon which administrative decisions must depend. The achievement of co-operation among the many able men needed to guide these various activities has been the work of an applied mathematician, Prof. P. C. Mahalanobis, formerly professor of physics, acting as honorary secretary to the Institute. He was this year elected fellow of the Royal Society.

There can be no doubt that accurate knowledge by the Government of Bengal of the amount of rice available in the Province would have obviated the food crisis of 1943, in which approximately one million lives were lost, by forestalling panic and cutting the ground from under the food speculators. The story is told in the report for $1943-44$ :

"The most notable progress in the year under review was achieved in the sample survey of crops. It would be remembered that work was started on a small scale with a total expenditure of about Rs. 7,000 on an exploratory survey of the jute crop in Bengal in 1937. This was the beginning of a five-year scheme for the improvement of jute statistics which was financed jointly by the Indian Central Jute Committee and the Government of Bengal. The'sampling technique, developed in the course of a gradually expanding series of surveys culminating in the full scale provincial work of 1941, which demonstrated beyond dispute the possibility of securing by this method a final estimate of jute acreage with a margin of error of only two or three per cent at a cost of one-fifteenth or one-twentieth of that of a complete enumeration. A general account of the five-year scheme with discussion of theoretical foundations was given in a memoir prepared by the Hon. Secretary in 1942 which is being published in the Philosophical Transactions of the Royal Society of London.

"The Hon. Secretary had been pressing from the very beginning of the five-year scheme in 1937 for the extension of the method to cover paddy and other important crops in Bengal. Each year from 1938 to 1942 he repeated his efforts but without success. In 1942 the Indian Central Jute Committee had expressed their complete satisfaction with the method of the sample survey and had recommended its continuance by Government in future. The Government of Bengal however decided at first to discontinue the work but subsequently revoked their decision and asked the Hon. Secretary at the end of March 1942 to proceed with the Jute survey. By this time a good portion of Burma had been occupied by the Japanese, and the supply of rice from that country had been cut off. Apprehending a serious deterioration in the food situation (not because of the physical volume of the import which was small but because of the possible effect on prices) the Hon. Secretary submitted a definite scheme to the Government of India at the end of March 1942 for extending the sample survey to cover the paddy crop in Bengal. In the course of the next few months he also discussed the question with a large number of officials in Bengal but all his efforts failed completely. In the absence of reliable statistics both the provincial and the Central Governments were left entirely in the dark regarding the supply position of rice at the end of 1942. This made it impossible for Government to pursue a consistent food policy on any objective basis. The weakness of the statistical position was thus an important factor in bringing about the deplorable food crisis in Bengal in 1943."

It was not, therefore, until after the famine that the Institute was enabled to show what its organization could do with the immense problem of sampling the 70,000 square miles of agricultural Bengal. Adequate accuracy in areas under crops is much more difficult to attain than is yield for unit areas. Some 59,000 grids each of $2 \cdot 25$ acres, chosen on a system of stratified random sampling, were needed for Bengal, the whole being divided into zone cells of sixty-four square miles and sub-cells of one square mile, approximately the area occupied by a single village. A feature of great importance for Indian conditions, and worthy of study elsewhere, is the duplication of the system in interpenetrating networks, so that entirely independent pairs of estimates are available for each area. This not only facilitates the administrative checking of gross negligence, or misunderstood instructions, but also enables the precision of the final estimate to be assessed as it really is by including all causes, human as well as physical, which contribute to inaccuracy in the result.

There is perhaps no other organization in which practical and theoretical work are more thoroughly integrated. The combinatorial investigations of R. C. Bose and A. Bhattacharya and the studies of multivariate distributions of Mahalanobis and S. N. Roy supply not only the general plan but also very detailed guidance to the two hundred or so workers of the field and computing staffs.

\section{EXCAVATIONS AT HYRAX HILL, NAKURU, KENYA COLONY}

$A$ LTHOUGH uncertainties in detail may still exist, the general structure of the prehistoric story of Kenya as laid down by Dr. L. S. B. Leakey is now accepted by most prehistorians. The various climatic changes that have occurred and their correlations with the more important cultures found are also clear. Following on a major pluvial phase called Gamblian and correlated with the Kenya upper palæolithic, there were two merely wet phases separated by a dryer period. These are known respectively as the Makalian and the Nakuru wet phases. They are post-palæolithic in age, and the latter is not of great antiquity. 


\section{No. 3972 December 15, $1945 \quad$ N A T U R E}

Mary D. Leakey, in a paper entitled "Report on the Excavations at Hyrax Hill, Nakuru, Kenya Colony, 1937-1938" (Trans. Roy. Soc. S. Africa, 30, Pt. 4), describes excavations made at sites on an eminence which was under water during the period covered by the last major pluvial (Gamblian), and along the sides of which occur beach-levels of the subsequent wet phases. Correlation of the archæological and geological records is therefore simple. A number of sites, including some stone-walled enclosures and a low mound, were investigated, as well as a group of pit dwellings. There were found : (1) a neolithic occupation site and cemetery, (2) a Gumban (neolithic) pit-dwelling village, and (3) a later, probably not very ancient, level connected with the stone-walled enclosures and associated burial pits and with an industry which shows the influence of Arab traders.

The neolithic occupation site lies on the 335-ft. beach (Makalian) and is therefore subsequent to its formation; the Gumban pit-dwelling is somewhat younger in age and contains an industry (Gumban $B$ ) which is well known elsewhere and has been assigned to the maximum period of the later (Nakuru) wet phase. From the earlier neolithic levels there were brought to light no less than eighteen skeletons-a number female-in contracted burials. These are described in detail by Dr. Leakey.

The associated industry clearly shows its upper palæolithic origin, for it must be remembered that in East Africa there were no devastating climatic changes of the magnitude of those which obtained in Europe; cultures were not swept away but ripened and went to seed; the past continued to influence the growth of the present much more than was the case in Europe. Thus in the levels above mentioned, there were found a whole series of obsidian tools clearly derived from normal Kenya upper palæolithic types. In the Gumban levels there were stone bowls and pottery typical of the Gumban $B$ neolithic.

The report contains 409 pages and is well illustrated. All concerned in the post-palæolithic cultures of Kenya will find it very interesting.

\section{C. BurkitT.}

\section{AUTOMATIC CONTROL AND RECORDING IN CHEMICAL AND OTHER PROCESSES}

$\mathrm{T}$ HE Institution of Chemical Engineers, the Institute of Physics and the Chemical Engineering Group of the Society of Chemical Industry made arrangements more than a year and a half ago to hold a joint conference in the autumn of 1944 on recording and controlling in the chemical industries. The incidence of flying bombs and of rockets, however, made it inadvisable to gather together a large number of key technicians in London at that time, and the conference was postponed indefinitely. This has proved to be a fortunate circumstance; for the conference was held on October 19 of this year, when the industries interested were not completely occupied. with war-time requirements, but were turning their attention once again to the problems of ordinary commercial production. In consequence, the conference has been held at a time when industry is not merely aware of certain technical deficiencies but also is actually planning to do everything possible to overcome them. That the subject of the conference is of vital interest to the chemical industries, as indeed it is to all industries, was shown by the remarkable attendance, the lecture theatre at the Royal Institution being filled and almost over-filled. Apart from all other benefits which accrue from a conference of this kind, the personal contacts which are made between the makers and users of instruments provide ample justification for holding it, and it was a happy thought on the part of the organizers to arrange that the instrument firms should hold private exhibitions of their instruments on the following day.

In the opening address to the conference, given by the president of the Institute of Physics, Sir Frank Smith, two main points were made. The first was the interesting one that although in industry the scientific instrument is usually regarded as the handmaiden of industrial processes, experience shows that the emergence of a new type of instrument has often been responsible for the birth of a new industry. There is, for example, a great industry now in existence catering for the requirements of radar, and it is indisputable that radar, and the industry associated with it, could not and would not exist unless an instrument were available for measuring time intervals smaller than one millionth of a second. Some decades ago, Sir J. J. Thomson devised the first instrument capable of achieving such measurement. This was the cathode ray tube, which later became the cathode ray oscillograph. Without this instrument, and without also the wireless valve which was a development of an instrument (the one-way rectifier of Sir Ambrose Fleming), there could not have been any radar nor, in consequence, the great now industry which has developed around it. Equally spectacular examples could be cited; but it is probably true that nearly every big advance in industry has been the result of knowledge obtained in the first place by the use of a new instrument. There is, therefore, every incentive for industry to be instrument-conscious, apart from that arising from the benefits obtained by the use of instruments which is ancillary to industrial processes.

Britain has been warned, and is acutely aware, that the maintenance of its standard of living is dependent upon an increased export trade. The achievement of an increased export trade is dependent upon our ability to produce articles of exceptional and standard quality at competitive prices. The material articles which can be exported can be classed either as special products or as articles capable of being produced by mass-production methods. It is in the production of this latter category that a realization of the necessity of industrial instrumentation is essential. Only by the complete control of processes can an exceptional quality of product be made standard, and only by the avoidance of waste and the lowering of costs resulting from control can competitive prices be offered.

In some general observations on the use of recorders and controllers, the director of the British Scientific Instrument Research Association, Mr. A. J. Philpot, pointed out that the general industrial structure of Britain, with its preponderance of rela. tively small concerns, has been favourable to the creation and maintenance of a system based on the maximum use of individual craftsmanship and a large exploitation of personal knowledge and experience. Such a system served us well during a long period when industrial processes were relatively 